\title{
Advances in confocal microscopy of the cornea
}

Confocal microscopy of the cornea in conscious human subjects is described in this issue. ${ }^{1}$ The technique is a remarkable modification of reflected light microscopy. ${ }^{2}$ It enables structures deep in living tissues to be examined at high resolution and contrast.

In conventional microscopy, much light is reflected from the surface of specimens and deeper structures can only be resolved by examining thin slices mounted on slides. Confocal images are thin 'optical' sections through the tissue, which remains functional and intact. Also, the confocal microscope is sensitive to minute changes in refractive index and, as a result, fixation and staining is not required. The methodology is a significant contribution to the available techniques for clinical and research work. It is capable of resolving detail in living conditions that previously could be seen only using electron microscopy of processed specimens. Ongoing physiological and pathological processes can be examined. Studies of changes during wound healing, disease processes and the response to treatment can be performed in individual patients.

Prydal et al. ${ }^{1}$ describe optical and computer methods to examine cellular structure of the corneal stroma. Digital image analysis is used to measure density and size of keratocytes. These techniques have been used to examine changes in keratocyte morphology and the formation of scar tissue after excimer laser photokeratectomy for myopia., ${ }^{3,4}$ The confocal microscope has also been used to diagnose cases of keratitis. ${ }^{5}$

The theoretical possibility of using confocal microscopy has been realised for several decades. However, it has only recently been possible to develop a system to examine eyes of conscious humans. The equipment is very different from earlier conventional microscopes. Light levels are low and images blurred due to eye movement. They can not be viewed through an eyepiece. Special optical devices, supersensitive video cameras and computer processing are necessary to give clear images. The problems are similar to those of astronomical imaging. Objects can not be seen by the naked eye, but can be revealed by optical and computer processing.
Confocal microscopy was invented by Minsky in $1955 .{ }^{6}$ He built the first confocal microscope, although images were too transient for it to be of practical use. In 1960 Petran built the first functional microscope. ${ }^{7}$ The object was illuminated by several points of light at one time, each the image of a small hole in a disc. Light reflected from illuminated spots in the tissue were imaged in another 'confocal' hole on the opposite side of the disc, filtering out light reflected from above and below the plane of focus. Such out-of-focus reflections would otherwise have obscured detail that was in focus. The disc rotated to scan the object and build up an image. This design was called the Tandem Scanning Confocal Microscope (TSCM). A particular advantage was that images could be viewed through the eyepiece in 'real time'. However, they were dim, only just visible to the fully dark-adapted eye.

Maurice, ${ }^{8}$ in 1968, described a form of confocal microscopy in which half the objective lens was used for illumination and half for observation. Later, resolution was improved by using two stationary slits in each light path. The specimen was advanced across the illuminated slit. ${ }^{9}$ Improvements in the methods used to scan the object have led to instruments suitable for clinical use: the specular microscope. ${ }^{10,11}$ They give images of the surfaces of epithelium and endothelium, but are limited to examining outer and inner layers where the change in refractive index is larger than within the cornea, and thus more light is reflected. In 1988 Dilly in collaboration with Boyde, Wright and Lemp ${ }^{12}$ modified a confocal microscope built by Petran and was able to image cornea in conscious humans. Fleeting glimpses of epithelium, endothelium as well as cells within the stroma were observed. However, they were too brief to be recorded with the systems available at that time. Prydal et al. ${ }^{13,14}$ used a prototype Petran TSCM to measure the thickness of tear film and epithelium in animals. In immobile tissues highresolution images could be recorded using standard photographic methods, but exposures of up to 2 minutes were required. Examination of the cornea in human subjects was attempted using sensitive cooled and intensified CCD (charge coupled display) cameras, but images were limited to superficial layers of the cornea.
J.I. Prydal

Addenbrooke's Hospital Hills Road

Cambridge CB2 2QQ, UK

P.N. Dilly

Department of Anatomy

St George's Hospital

Medical School

London SW17 ORE, UK 
In 1993 Cavanagh and Petroll et al. ${ }^{15}$ described further modifications of Petran's design (Tandem Scanning Corporation, Virginia, USA). Particular care had been taken to ensure accurate optical alignment, the size and pattern of holes in the disc had been optimised and an objective built specifically for examining the cornea in conscious subjects. It was a substantial improvement, and with advances in video technologies it was possible to record images of high contrast and resolution throughout the cornea. One such microscope was used for the work reported in this issue.

The new structures and functions that can now be examined provide opportunity for diagnosis and understanding of many conditions in which little development has been possible in the past. With continuing advances in optical, engineering, imaging and computer methods, confocal microscopy may become a standard instrument for clinical examination of the cornea.

\section{References}

1. Prydal JI, Franc F, Dilly N, Kerr-Muir MG, Corbett MC, Marshall J. Keratocyte density and size in conscious humans by digital image analysis of confocal images. Eye 1998;12:337-42.

2. Petran M, Hadravsky M, Benes J, Kucera R, Boyde A. The tandem scanning reflected light microscope. I. The principle, and its design. Proc R Microsc Soc 1985;20:125-39.

3. Corbett MC, Prydal JI, Verma S, Oliver KM, Pande M, Marshall J. An in vivo investigation of the structures responsible for corneal haze after PRK, and their effect on visual function. Ophthalmology 1996;103:1366-80.
4. Prydal JI, Kerr-Muir MG, Marshall J. Confocal microscopy with digital image analysis of the distribution and size of keratocytes in the cornea of conscious human subjects. J Physiol (in press).

5. Winchester K, Mathers WD, Sutphin JE, Daley TE. Diagnosis of Acanthamoeba keratitis in vivo with confocal microscopy. Cornea 1995;14:10-7.

6. Minsky M. Memoir on inventing the confocal scanning microscope. Scanning 1988;10:128-38.

7. Petran M, Hadravsky M, Egger MD. Tandem scanning reflected light microscopy. J Opt Soc Am 1968;58:661-4.

8. Maurice DM. Cellular membrane activity in the corneal endothelium of the intact eye. Experientia 1968;24:1094-5.

9. Maurice DM. A scanning slit optical microscope. Invest Ophthalmol Vis Sci 1974;13:1033-7.

10. Laing RA, Sandstrom MM, Leibowitz HM. In vivo photomicrography of the corneal endothelium. Arch Ophthalmol 1975;93:143-5.

11. Bourne WM, McCarey BE, Kaufman HE. Scanning mirror microscopy with optical sectioning characteristics: applications in ophthalmology. Appl Opt 1980;19:1749-57.

12. Dilly PN. Tandem scanning reflected light microscopy of the cornea. Scanning 1988;10:153-6.

13. Prydal JI, Artal P, Woon H, Campbell FW. Study of human precorneal tear film thickness and structure using laser interferometry. Invest Ophthalmol Vis Sci 1992;33:2006-11.

14. Prydal JI, Campbell FW. Study of precorneal tear film thickness and structure by interferometry and confocal microscopy. Invest Ophthalmol Vis Sci 1992;33:1996-2005.

15. Cavanagh HD, Petroll WM, Alizadeh H, He Y, McCulley JP, Jester JV. Clinical and diagnostic use of in vivo confocal microscopy in patients with corneal disease. Ophthalmology 1993;100:1444-54. 